\title{
Identification of active ingredient of codonopsis cordifolioidea by n-butyl alcohol
}

\author{
Yunpeng Luan ${ }^{1^{*}}$, Shuangqing Zheng ${ }^{2}$, Yanmei $\mathrm{Li}^{3}$, Qiming Wang ${ }^{4}$ \\ Project Sponsored by: Opening Fund Program of Yunnan Biology Advantage Distinctive Key Discipline \\ ${ }^{1}$ College of Life Sciences,Southwest Forestry University China 650224 Email:y_luan@126.com, \\ ${ }^{2}$ KPC Pharmaceuticals, Inc China,
}

Keywords: Codonopsis cordifolioidea, Active ingredients, N-butyl alcohol,Separation,chromatography

\begin{abstract}
Current Codonopsis cordifolioidea products are mostly its crude extract, which is of low technology content and low added value, and studies on the active ingredients of Codonopsis cordifolioidea are very limited. To promote industrial development of Codonopsis cordifolioidea product and to increase its technology content, basic researches on this plant shall be enhanced, including identification of its original species, establishment of appropriate animal model, separation and tracking of the active components, clarification of the mechanism of its effect to replenish qi and nourish blood, and identification of its effective parts and active ingredients, thus to lay the basis for establishment of the standards for Codonopsis cordifolioidea as a medicine. This study seeks to isolate the active ingredients of Codonopsis cordifolioidea. Methods: $95 \%$ ethanol was used for initial crude extraction, the solution was further extracted with petroleum ether and n-butanol by chromatography, and the n-butanol portion was eluted by gradients of chloroform-methanol (98:2 70:30). Results and conclusion: three elution peaks were detected at $37 \mathrm{~min}, 1 \mathrm{~h} 10 \mathrm{~min}$, and $1 \mathrm{~h} 39 \mathrm{~min}$, and three components: E, $\mathrm{F}, \mathrm{G}$ were identified. These results indicate that 3 active ingredients can be isolated from raw Codonopsis cordifolioidea material by n-butanol chromatography following soxhlet extraction.
\end{abstract}

Codonopsis cordifolioidea belongs to campanulaceae. Codonopsis belongs to the root of Codonopsis cordifolioidea(Codonopsis cordifolioidea P. C. Tsoong). Codonopsis cordifolioidea contains flavone cumarin, volatile oil, sugar, amino acid, protein,alkakloid, organic acid, tannin, phenols, resin and a small amount of saponin. Flavone cumarin is the main part of Codonopsis cordifolioidea ${ }^{[1]}$. In Yunnan, Codonopsis cordifolioidea can be divided into cultivated one and uncultivated one. Most of them in the market are cultivated. And the history of cultivating Codonopsis cordifolioidea lasts for almost a century. Codonopsis cordifolioidea, which is widely spread in Yunnan, has a high productivity and decent price. It can be easily found in the autumn market of Yunnan with a high sales volume. It has a long application history and broad-based popularity in Yunan. It can strengthen the middle warmer and benefit vital energy, moisten lung and stop cough. It is used as a cheap supplement in Yunnan and sells well in winter market. Compared with other codonopsis, it can also exclude the pneumatosis in human body ${ }^{[2.3]}$.

Codonopsis cordifolioidea, surface smooth and hairless, seta sparse and short, root invisible, stem 
twining, ca.1 meter high, 3-4 millimeters in diameter, with sparse and short branches. Main stem has sparse alternate leaves of about 5 to 9 centimeters long. Distance within the leaves is about 10 centimeters, petiole linear. Leaves large, broadly ovate, 10 by 7 centimeters. The top of the leaves are tapering or acutus, upper leaves green, lower leaves greylish-green, heart-shaped root, distinct veins, margin entire. Top shoot have two opposite leaves, short petiole, less than one centimeters long,similar to the leaves in main stem. Flowers solitary, develop from outer axil. Pedicels intergrowth with leaves, ca. 3-6 centimeters long. Calyx adnate to middle ovary, tube hemisphere- shaped, valves triangular-lanceolate shaped, ca. 1 centimeter long,5-6 centimeters wide, apex taper, entire margin; corolla mitriformed, ca. 1.7-1.8 centimeters long, ca.1-1.2 centimeters in diameter, apex half supersulcus, valves triangular-lanceolate shaped, dark blue; filament base expanded, ca. 5 millimeters long. Anther is also about 5 millimeters long. Capsule lower half hemisphere- shaped, upper half rostellate, ca. 1.5 centimeters in diameter. Seeds numerous, elliptical, dinky, brown, indistinct net veins, flowering fruit bearing period $9-10$ months $^{[4]}$.

\section{Apparatus and materials}

Apparatus:

Analytic balance $\mathrm{c}=10 \mathrm{~d} \operatorname{Max} 220 \quad \mathrm{~d}=0.001 \mathrm{~g}$

One set of Soxhlet extractor $(500 \mathrm{ml}$ round-bottom flask, $100 \mathrm{ml}$ Soxhlet extractor rotary evaporator, matched condenser pipe )

Rotary evaporator RV8 032014 (IKR Company)

MA99-2A automatic nucleic acid protein separation chromatograph system configuration: One HD-2 nucleic acid protein detector, one BS-100A automatic fraction collector, one BT-100 constant flow pump, one TH-500 gradient mixing device, one XWT-S desktop recorder, one set of standard chromatographic column ( one $1.0 * 40$ general chromatographic column, one $1.6 * 50$ general chromatographic column, one $2.5 * 60$ medium-pressure chromatography column )

Reagent:

Column-layer chromatographic silica gel particle size: 200-300 mesh

Ethanol(95\%) Analytically pure Batch number: May, $2^{\text {nd }}, 2013$ Executive standard: GB/T 679-2002, License Number: (Dian) XK13-011-00001-38

N-butyl alcohol Analytically pure Batch number: October, 15 ${ }^{\text {th }}, 2014 \quad$ Executive standard:GB/T 12590-2008, License Number:XK13-201-00115

Trichloromethane Analytically pure Executive standard:GB/T 682-2002, License Number:XK13-011-00001-34

Acetone Analytically pure Batch Number:20111203 Executive standard:GB/T 686-2008 License Number: (Dian) XK13-011-00001-24

Methanol Analytically pure Executive standard:GB/T 683-2006 , License Number:(Chuan)XK13-011-00015

Petroleum ether $\left(60 \sim 90^{\circ} \mathrm{C}\right)$ Batch Number:013092601 Executive standard: GB/T15894-2008,

License Number: XK13-201-00306

Plant Material:

Raw Codonopsis cordifolioidea for $1000 \mathrm{~g}$, (market raw Codonopsis cordifolioidea, originate from Yiliang, Yunnan, planted by local farmers, purchased in January 2015)

\section{Extraction and Separation}

\subsection{Extraction of the active ingredient of Codonopsis cordifolioidea}

Preserve the raw Codonopsis cordifolioidea(10000g) in ultra cold storage freezer of $-70^{\circ} \mathrm{C}$. When used, unfreeze and clean the raw Codonopsis cordifolioidea in normal temperature, airdry the water on the surface of the raw Codonopsis cordifolioidea in a dry, ventilate and shade place. Then slice the raw 
Codonopsis cordifolioidea, weight the raw Codonopsis cordifolioidea by scale for $50 \mathrm{~g}$ and put them into the Soxhlet extractor of $100 \mathrm{ml}$, take $300 \mathrm{ml}$ of ethanol $(95 \%)$ by measuring cylinder and put the ethanol into the $500 \mathrm{ml}$ round-bottom flask. Install the Soxhlet extractor and check leakage. After confirming that the equipment is in good condition, connect condensed water, turn on the water bath and set the temperature to $78^{\circ} \mathrm{C}$ and reflux extract for three times. Use rotary evaporators to decompression and recycle extracting solution to decompress and recycle slovent, obtain $2 \mathrm{~g}$ of extractive.

\subsection{Separation of active ingredient of Codonopsis cordifolioidea}

Add $10 \mathrm{ml}$ of distilled water suspension to the $2 \mathrm{~g}$ of extractive, put them into the $50 \mathrm{ml}$ separating funnel and put $10 \mathrm{ml}$ of petroleum ether into the separating funnel for extraction. Operation procedure:1 Leakage check, apply some vaseline on the frosting brim to avoid leakage. 2. Close the valve of separating funnel. Use one hand to hold the valve tight to avoid leakage, use another hand to to jam the upper vent tight. Place the separating funnel horizontally and shake it thoroughly to make the two liquid interact fully with each other. These two liquid cannot mix with each other. The full interaction can make the extractive fully dissolved by extraction liquid. Open the valve to release gas after shaking every one minutes, control and keep the air pressure in the separating funnel into a safety range. Keep the separating funnel being placed vertically after shaking it for three times until the boundary of the two liquid remain clear and static. 3. Open the valve, release the lower liquid from the lower vent, and release the upper liquid from the upper vent. Use $10 \mathrm{ml}$ ethyl acetate to extract the extracted water and obtain ethyl acetate. Use $10 \mathrm{ml} \mathrm{n}$-butyl alcohol to extract extracted the water extracted by ethyl acetate and then obtain n-butyl alcohol. Use chloroform methanol to gradient elute the obtained n-butyl alcohol.

\subsubsection{Preparations}

2.2.1.1 Set up system circuit and fluid circuit system

2.2.1.2 Turn off electricity, set measurement wavelength of the installing hole of optical filter to $280 \mathrm{~nm}$, use optical filter box of $280 \mathrm{~nm}$ wave length. Plug wave length digit face-up into the hole.

2.2.1.3. Turn on the electricity of detector, and preheat it for 30 to 60 minutes.

\subsubsection{Sample(liquid)flow direction and tube coupling}

Buffer the liquid or sample $\rightarrow$ chromatography column $\rightarrow$ entrance(upper) $\rightarrow$ chromatography column(lower) $\rightarrow$ detector entrance(lower) $\rightarrow$ detector exit(upper) $\rightarrow$ constant flow pump $\rightarrow$ collect testing tubes

\subsubsection{System debugging}

\subsubsection{Detector debugging}

(1) Preheat instrument for 30-60 minutes and then debug the instrument

(2) Check the wave length of detector

(3) Switch "Sensitivity"to "T"gear and the indicator light for "T"gear lights, adjust the rotary knob to " 100 "(now the penetration rate for " $T$ "is $100 \%$, and display screen shows " 100 ")

(4) Switch "Sensitivity"to " $1 \mathrm{~A}$ "gear and indicator light for "A"gear lights, adjust the "adjust"rotary knob and turn "A"to zero. (Now the penetration rate for "A"is $100 \%$, and display screen shows " $100 ")$

(5) Weigh 40g of column-layer chromatographic silica gel(200-300 mesh) by analytical balance and put them into $100 \mathrm{ml}$ beaker, measure $40 \mathrm{ml}$ of trichloromethane and put them into the beaker. Use a glass rod to fully stir the liquid until no obvious particles can be seen. Put the blended liquid into a $1.6 * 50$ general chromatographic column in a coherent way.Then turn on constant flow pump power, adjust flow speed to $1 \mathrm{ml} / \mathrm{s}$, make buffer liquid flow past the cuvette of detector to wash column. Use wood stick to tap chromatographic column to exclude the bubble in it. Adjust "T" gear rotary knob to "100", Adjust "Zero Set" gear rotary knob to "100",to make absorbency "A" change to " 0 ". Now the system has reached to equilibrium. When the sample flow pass the detector, the atlas drew by 
computer shows a straight line paralleling to x-axis. This means the column has been washed up and are ready for testing.

\subsubsection{Collector debugging}

(1)Preparations

Install and fix power line, test tube basket, vertical stick, safety valve, leakage alarming board. Turn on power, test tube tray resumes to starting point, LCD lights, displays in Chinese. Press any key and enter standby mode.

(2)Locating water dropper

Adjust water dropper to the central part of the first test tube(the first test tube in the outer ring), tighten three set screws(use set screw to fix horizontal stick, safety valve and vertical stick).

(3)Parameter setting

Set beginning tube number, beginning time and terminating time. Set collecting time to one tube per minute.

\subsubsection{Loading Sample}

When the buffer solution on the chromatographic column is drying up, use water dropper to absorb sample and add 3-4 drops to the chromatographic column. Add eluant when the sample are flowing down and drying up, the level of eluant should be $1 \mathrm{ml}$ higher than column.

Close the mixing output valve of gradient mixing device, pour concentrated solution into the left beaker, open mixing valve to let the solution flow to the right beaker, close mixing valve immediately, pour another dilute solution into the right beaker, keep the two liquids in same level, open mixing valve, keep the two liquids leveling off, slowly adjust output flow according to given slope.

\subsubsection{Image drawing}

$\mathrm{N}$-butyl alcohol is gradient eluted by chloroform methanol(98:2 $70: 30)^{[5]}$. three parts including E,F,G.

\section{Experimental results}

Figure 1 N-butyl alcohol chromatography figure

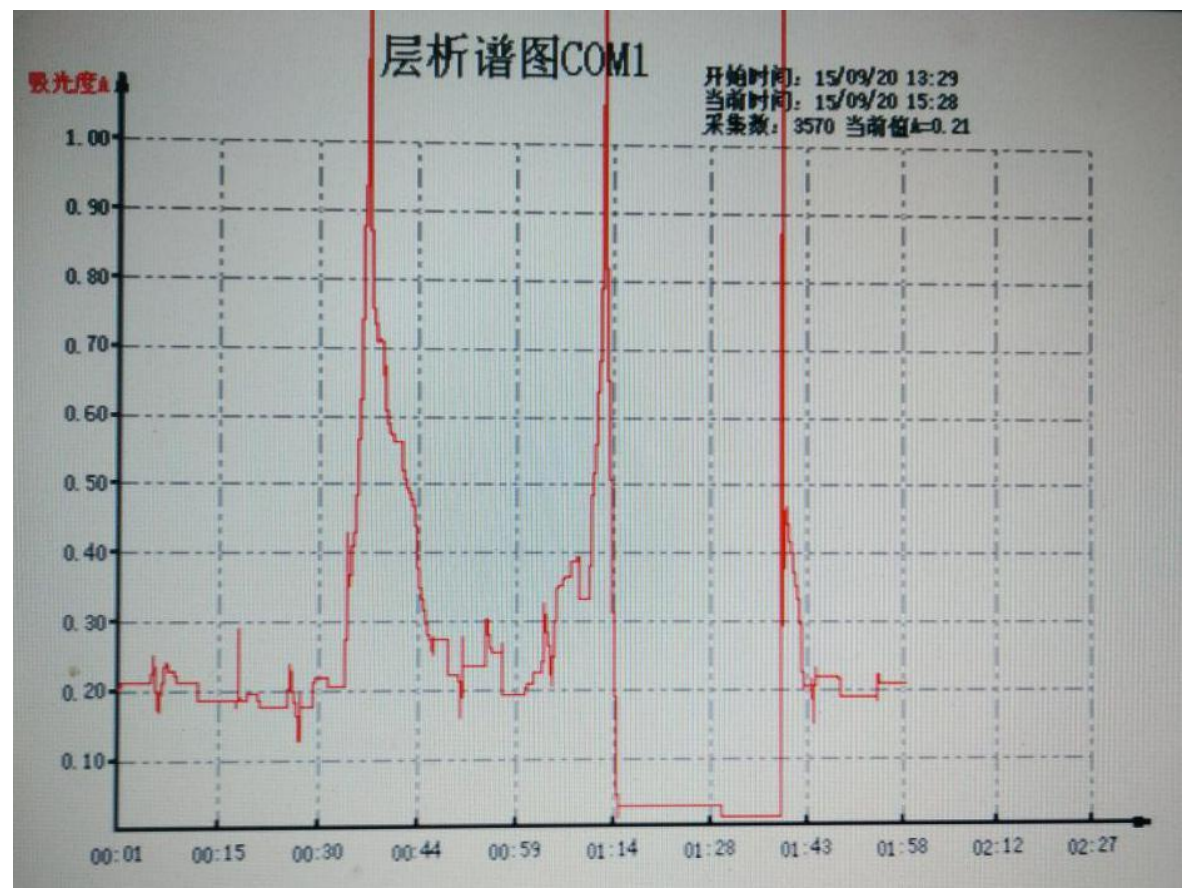


The first wave crest appears at 00:37, it shows chromatography obtains the first high content ingredient. The second wave crest appears at 01:10, it shows chromatography obtain s the second high content ingredient. The third wave crest appears at 01:39, it shows chromatography obtains the third high content ingredient. The figure gradually level off to the horizontal axis. This experiment shows that three active ingredients can be extracted from n-butyl alcohol through Soxhlet extraction.

\section{References}

1.CHEN Zi-jun1, LI Yun-sen2, LU Lan1, LU Bing1, ZHOU Ji-yan1, HU Yue-juan1.Pharmacodynamic Study on Qi-Blood-Enriching Effects of Codonopsis Bulleynana Forest ex Diels. [J]Shanghai Journal of Traditional Chinese Medicine,2009,43: 68-72.

2.Li SZ,Ye GZ. Preliminary studies on Codonopsis bulleyana Forest ex Diels. [J ]Yunnan College Trad Chin Med, 1994, 17: 17220.17-20

3.Chen ZQ ,Wei QH,Zhou JY. Research progress of Chou2Shen. Yunnan J Trad ChinMed Materia Medica,2006, 27: 19220.18-21

4.MEI Ren-qiang; LU Qing; HU Yan-fen; CHENG Yong-xian, Chemical Constituents from Codonopsis cordifolioidea[J].Natural Product Research and Development, .2010, 22:238 -240

5.Cheng YX.Chemical constituents from Cucubalus baccifer, Brachystemm a calycinum and three Magnoliaceae plants . Kunming: Kunming In stitute of Botany Chinese Academy of Sciences,PhD.2000 